\title{
Summary of the Camshaft Grinding Machine and the Finite Element Analysis of grinding wheel rack frame
}

\author{
Jinwei Fan,HongliangWangandLanqing Zhang \\ School of Mechanical Engineering, Beijing University of Technology, Beijing100124, China. \\ jwfan@bjut.edu.cn,977714868@qq.com,1002878319@qq.com
}

Keywords: Camshaft Grinder; Grinding Wheel Rack Frame; 3D Modeling; Finite Element Analysis.

\begin{abstract}
The camshaft grinding is precision machine tool. This paper discusses on the necessity of finite element analysis. This paper briefly introduces the camshaft grinding machine structure, and compared the emulation of grinding and tangent point tracing grinding camshaft two grinding methods, The benefits of motorized spindle, support bearing, feed system and the application of $\mathrm{CBN}$ grinding wheel for high speed grinding are introduced in detail. Using Pro/E software to establish a certain type of 3D model of camshaft grinding machine for grinding wheel rack frame, and using the finite element analysis software ANSYS to the grinding wheel rack frame for the statics analysis and modal analysis. Finally, static analysis and modal analysis results of casing strength checking of grinding wheel frame and structure optimization provides an important basis.
\end{abstract}

\section{Introduction}

Camshaft is one of the key parts of the engine. Its surface contour is very complex, and has a high requirement on the machine. In order to ensure good smoothness of engine, request processing quality of camshaft must meet the precision requirements. Along with the progress of science and technology and mechanical industry rapid development, to the requirement of the camshaft machining quality become more and more high. The end of the camshaft machining procedure is done by grinding machine. The main factors influencing the precision of CAM profile have geometric accuracy of grinding machine, deformation of grinding, grinding heat,servo system error and deformation of grinding, etc.[1]. Geometry precision of grinding machine directly affect processing qualityof the camshaft.It is the foundation of improving camshaft machining accuracy. To improve the quality of the camshaft machining it is necessary to analyze the camshaft grinding machine.

\section{2 summary of camshaft grinding machine}

Camshaft grinding is mainly divided by imitating grinding method and tangent point tracking grinding method (also known as servo grinding method). When imitating grinding method is used to grinding workpiece, workpiece rotation is constant angular velocity. Although the structure is simple, but this kind of machine has many defects. The main defects are [2]: 1)Manufacturing of mother CAM and modelingare very complex, and require a long preparation cycle; 2)Because product is updatedquickly, so mother CAM and modeling need to be redesigned and manufactured again, with less flexible; 3)The precision of mother CAM and modeling directly affect the precision of workpiece.It is high for earlywork; 4) It has a great influence on machining error when grinding wheel is worn,without error compensation; 5) Rotation peed of grinding wheel is low, so the production efficiency is not high. Due to imitating grinding method has above defects, so as to promote the development of tangent point tracking grinding method. Generally the rotary motion of workpiece is known as $\mathrm{C}$ axis in grinding process. Transverse feed movementof grinding wheel is known as $\mathrm{X}$ axis.Working principle of tangent point tracing grinding method is through program control $\mathrm{C}$ axis and $\mathrm{X}$ axis to keepthe cylindrical of grinding wheel and the outline of complicated workpiece surface tangent, Ensuring the cutting thickness is the same, so that the surface of CAM contour is processed out [3]. For the traditional machining method, workpiece is constant angle of rotation.Linear speedof each point on the contouris changing with the change of rotating radius, 
directly affect the roughness on the surface of the camshaft. Material removal rate of grinding workpiece surface also as the outline of the change of radius, have taken place great changes. That cause grinding force fluctuations andcontour error.Tangent point tracking is constant in grinding, made up for by imitating grinding the above defects. Tangent point tracking is constant in grinding, so itmade up for by imitating grinding the above defects.

$\mathrm{CNC}$ camshaft grinding machine is mainly composed of lathe bed, grinding wheel rack, head and tail frame, cooling system, lubricating system, electric control system, hydraulic system and $\mathrm{CNC}$ system and so on several parts. Grinding wheel rack is controlled by CNC system to realize the camshaft grinding and radial feed [4]. It is mainly composed of grinding wheel rack enclosure, spindle system, feed system, cooling loop, static pressure oil circuit, wheel bearings, and the clamping device, etc. The traditional spindle system is driven by servo motor through a belt, coupling, etc. The spindle is supported by ball bearings. Feed system is driven by servo motor and ball screw make rotation movement change linear feed movement.Transmission ratio of belt drive is not accurate and is big device structure size. It is low transmission efficiency. The bearing capacity of the ball bearing is low andshort service life. There is gap between ball screw and nut. With the development of technology and enhancing the machining accuracy of grinding machine, the application of motorized spindle is more and more widely. Motorized spindle motor is be placed within the spindle system and motor directly drive wheel,and it removed the intermediate transmission link.It not only makes the structure becomes compact, but also makes mechanical efficiency and rotation accuracy improve [5].Static and dynamic pressure bearings, precision angular contact ceramic ball bearings, air bearings and magnetic suspension bearingsare often used to support the motorized spindle [6]. Air pressure is a new type of bearing of motorized spindle used to support air bearing. When spindle is rotation, it isno mechanical contact with bearing. So wear and teararereduced, and it owns high speed and no pollution, but device of system is complex, and sealing requirement is high. The pressure value is small, low bearing capacity,generally used in high speedand light load. Magnetic suspension bearing is the use of electromagnetic force to make motorized spindle suspend.When it is movement without mechanical contact with the spindle, and there is no friction, with high speed, low energy consumption, low noise, long life, no lubrication, no oil pollution, etc., but electrical control system of the magnetic suspension bearing is complex, and cost is high. There is currently no application in batches in industry. Angular contact ceramic ball bearing has high hardness, high wear resistance, oxidation resistance, low temperature rise, high speed, etc. Its top speed is as high as above100000 $/ \mathrm{min}$ and it can withstand the power of more than $30 \mathrm{KW}$.Static and dynamic pressure bearings is a new type of oil film bearing. It has the advantages of the fluid dynamic pressure bearing and hydrostatic bearing,large carrying capacity, the system rigidity. When starting and stopping, also can form the oil film lubrication, make spindle wear easily. Feed system is driven by linear motor, so reducing the error of the ball screw and nut clearance.

With the development of lightweight direction, cars and internal combustion engines, motorcycles, etc., required engine must have better dynamic characteristics. Camshaft grinding technology is developing to high precision, high efficiency, high flexible, high reliability, etc., and ordinary class of alumina grinding wheel has been unable to meet the requirements. Through the investigation at home and abroad, high speed servo camshaft grinding machine almost all adopt the CBN grinding wheel. CBN grinding wheel with high hardness, high temperature resistant, high quality, good thermal conductivity and long service life, low cost, easy to repair, it has incomparable superiority in the ultra-high speed grinding and grinding difficult to machining materials [7]. CBN grinding wheel during grinding due to thermal conductivity is good, a lot of heat through is generated by the grinding wheel, reducing the grinding zone temperature, reducing the thermal stress and thermal deformation of grinding and the trend of grinding burn artifact. CBN grinding wheel compared with ordinary alumina grinding wheel,grinding area heat reduces about $2 / 3$. The above characteristics of CBN grinding wheel for high speed grinding support [8].

Grinding wheel rack frame plays a supporting role in spindle system and built-in motor, and is a key structure of the CNC camshaft grinding machine [9]. Under the action of grinding 
force,grinding wheel rack frame must have enough stiffness, if the stiffness of the grinding wheel rack frame is not enough, that will destroy the bearing oil film, and cause the spindle stuck. Using the ANSYS finite element analysis was carried out on the grinding wheel rack frame,to check whether the strength meet the requirements, andto ensure the strength of the grinding wheel rack and improve grinding wheel frame rigidity. To realized lightweight design of grinding wheel rack. Modal analysis was carried out on the grinding wheel rack, and found out the workpiece machining error sensitive frequency to improve its structure.

\section{3 the finite element analysis of grinding wheel rack frame}

\section{1 grinding wheel rack frame geometry modeling}

Grinding wheel rack frame geometry modeling was drew by using Pro/E as shown in figure 1.From the figure can see one-piece bearing on both ends. It was separated among upper and lower machine parts used to place motor, mainly in order to help assembly and improve before and after bearings supporting stiffness.

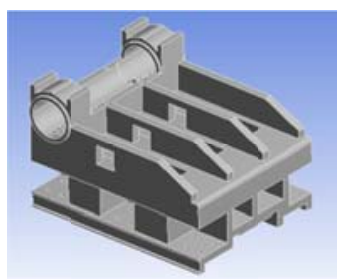

Fig1. Grinding wheel rack frame geometry model

Considering the complexity of structure of the grinding wheel frame, if direct finite element analysis not only spend time long, may cause cannot be analyzed, it is necessary to simplify its structure. To remove a few small convex platform, chamfering, holes and other small structure, make its structure simply, and The effects of it is not big the result of the analysis. The simplified model and the finite element model is shown in figure 2.

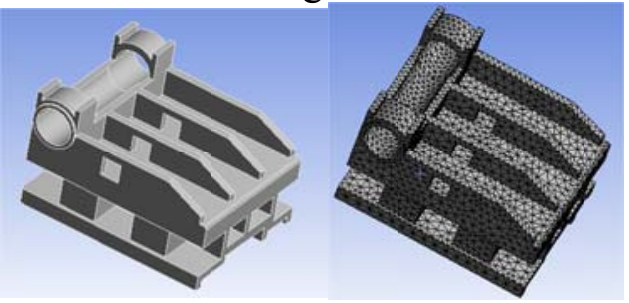

(a) Geometric model(b) finite element model

Fig2. Simplified grinding carriage body geometry model and finite element model

\section{2 finite element model of grinding wheel rack frame}

The simplified model is transformed into an intermediate format for the IGES into ANSYS software, the first set material is HT200, density for $7200 \mathrm{~kg} / \mathrm{m} 3$, Young's modulus for 120GPa, Poisson's ratio for 0.3. Finite element analysis of geometry, meshing is critical, and its quality directly affects the analysis of the results. When meshing is too thin, the results analyzedand the actual deviation can be quite large. When the meshing is too dense, not only the analysis time is too long, even may not be able to draw a result. Statics analysis than the modal analysis of the grid can be thinner some [10]. The analysis process is to model the meshing of larger, and record the results of the analysis. To refine the grid is analyzed, through the contrast, if the deviation is very big need to refine the grid again, until the results of the analysis and the previous deviation is not big.

CNC Grinding Machines Camshaft suffered load are: 1) Considering the quality of grinding wheel rack frame heavier, grinding wheel rack frame bears itself down gravity; 2) When grinding wheel rack is reciprocating motion, speed will cause inertia force, soabout $5 \mathrm{~m} / \mathrm{s} 2$ acceleration on the grinding wheel rack frame; 3) Reaction forcegenerated by grinding forces is mainly close to the grinding wheel on the side of the bearing,so when analyzing reaction of grinding forceshould exert on the front bearing. 4) When spindle is rotary motion, the system will generate friction bearing; 5) Considering spindle system is in bearing pedestal, it will generate downward pressure on the grinding wheel rack frame. 


\section{3 statics analysis of grinding wheel rack frame}

When it is the statics analysis of grinding wheel rack frame, the above load and constraints should exert on the grinding wheel rack frame. By viewing overall deformation and the equivalent stress nephogram of grinding wheel rack frame, result is shown in figure 3 (a) and (b). By figure 3 (a), maximum deformation of grinding wheel rack frame is $1.12 \mathrm{um}$. By figure 3 (b), maximum stress of grinding wheel rack frame is $0.82 \mathrm{MPa}$, and maximum stress occurs before the grinding wheel rack support on both sides of the bearing and the housing substrate corner part. Due to bearing inside also installs hydraulic bearing outer ring and the actual load is changing, so here of stress analysis and the actual stress is not completely consistent, but it can be used as a test grinding wheel rack frame whether it will have enough strength standard.

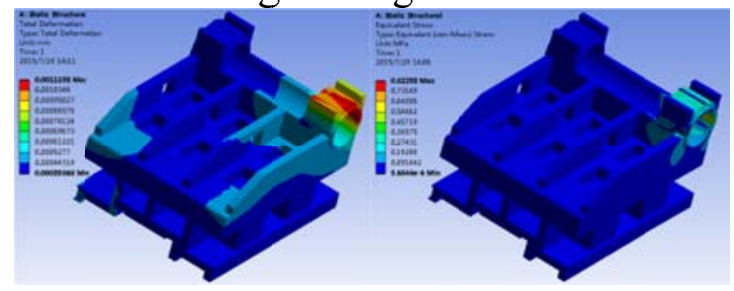

(a) total deformation displacement(b) equivalent stress nephogram

Fig3. Grinding wheel rack total deformation displacement and equivalent stress nephogram

\section{4 modal analysis of grinding wheel rack frame}

On the basis of the above statics analysis analyzes modal. In the first six order modal, vibration mode diagramswere as shown in figure 4. According to vibration mode diagrams and animation simulation, corresponding natural frequencies and vibration mode are as shown in table 1.

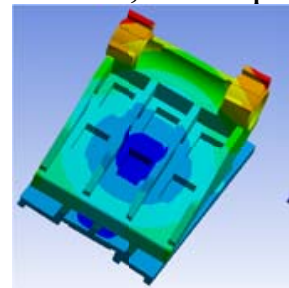

Step1

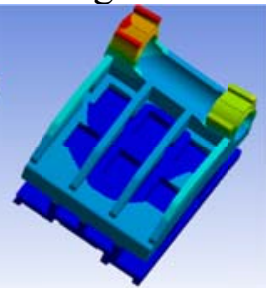

Step2

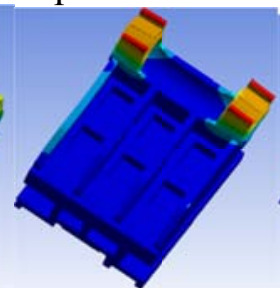

Step3

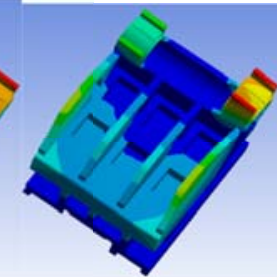

Step4

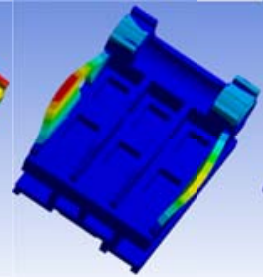

Step5

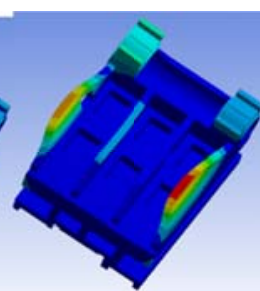

Step6

Fig4. Grinding wheel rack frame top six order modal vibration mode

Tab1. Grinding wheel rack frame inherent frequency and vibration mode

\begin{tabular}{ccc}
\hline $\begin{array}{c}\text { Order } \\
\text { number }\end{array}$ & $\begin{array}{c}\text { Natural frequency } \\
/ \mathrm{Hz}\end{array}$ & Vibration mode \\
\hline 1 & 507.54 & $\begin{array}{c}\text { Grinding wheel rack frame is the whole around Y shaft torsional vibration } \\
\text { Before and after grinding wheel rack bearings are reverse around X shaft } \\
\text { torsional vibration }\end{array}$ \\
3 & 605.18 & $\begin{array}{c}\text { Before and after grinding wheel rack bearings are same direction around } \\
\text { the } \mathrm{X} \text { shaft torsional vibration }\end{array}$ \\
4 & 665.44 & $\begin{array}{c}\text { Grinding wheel rack frame is the whole around X shaft torsional vibration } \\
\text { Grinding wheel rack before and after reinforcement plates reverse swing } \\
\text { along the X axis }\end{array}$ \\
5 & 689.05 & $\begin{array}{c}\text { Grinding wheel rack before and after reinforcement plates same direction } \\
\text { swing along the X axis }\end{array}$ \\
\hline
\end{tabular}

Known from the analysis of modal, the second order modal vibration mode of grinding wheel rack frame is grinding wheel bearing before and after reverse around $\mathrm{X}$ shaft torsional vibration. This will directly affects the radial displacement of grinding wheel rack, which affects the machining precision of camshaft.

\section{Structural optimization of grinding wheel rack frame}

The accuracy of machine tools plays a key role on the processing precision of parts. CNC grinding machine as precision machine toolmust have high precision. In order to guarantee the accuracy of machine tool, machine tool parts must have high precision, and in the assembly process to reasonable assembly can meet precision requirement. Grinding wheel rack frame as the key part 
of CNC camshaft grinding machine parts, to ensure that has enough accuracy, and precision should have good stability. Known from the analysis of the above: 1) reaction force is mainly composed of grinding force close to the grinding wheel on the side of the bearing, andit is damage easilyunder the action of heavy load. 2) Bearing seat will bearfriction that is produced by the rotation of the spindle system.Friction will wear machining surface of bearing seat in the process, and causing the precision of grinding wheel rack frame become low; 3) the first natural frequency is sensitive to frequency for machining error.The above three conditions will all cause the machine precision become lower.

In order to improve the stability of the machine tool accuracy, author puts forward the following suggestions to optimize.

1) By increasing near the wheel side bearing wall thickness to improve the grinding carriage body strength;

2) Coating a layer of wear-resistant materials in bearing hole surface to improve the resistance for wearing;

3) Isolating vibration frequency at about $507.54 \mathrm{~Hz}$ or so vibration source or increasing the reinforcement to increase the wall thickness of sensitive frequency values.

\section{Conclusion}

This paper briefly described two methods of grinding camshaft grinder. By using Pro/E for a certain type of grinding wheel rack framefor geometry modeling and using ANSYS finite element software for static and modal analysis, analysis of the grinding wheel rack frame.Analysis of the grinding wheel rack frame deformation size in the process of grinding, equivalent stress, the first six order natural frequency and modal vibration mode. Through the size of deformation and stress of intensity that provide a basis for the structural optimization. Through grinding wheel rack frame before 6 order modal vibration mode and frequency analysis of the grinding wheel rack frame dynamic characteristics in the process of grinding, so as to find out the frequency of the biggest influence on grinding wheel rack frame, to isolate with frequency vibration sources and provides a theoretical basis for structure optimization.

\section{Acknowledgments}

The national natural science fund project, Reverse to track the root cause of the defects on CNC machining theory and experimental research (51275014)

\section{References}

[1] Liu Yong-jun, Fan Jin-wei, Li Yun. The engine camshaft grinding deformation compensationtechnology research[J]. Journal of agricultural machinery,2013,44(6):274-279.

[2] Xiao Zhen-jian. The mathematical model of CNC grinding machine for grinding camshaft parts and experimental research[D]. Hunan:Hunan university,2001.

[3] Guo Li, Sheng Xiao-min. Tangent point tracking grinding camshaft part analysis[J]. Precise Manufacturing and automation,2010,(1):13-19.

[4] Zheng Meng-kun. High speed and high precision camshaft grinding machine grinding wheel frame optimization design[D]. Hubei:Huazhong university of science and technology,2012.

[5] Shen Wei. Introduction to technology and application of motorized spindle[J].Equipment management and maintenance,2010,(9):45-46.

[6] Wang Chun-hao. New type of dynamic and static pressure bearing design and performance analysis[D]. Beijing:Beijing university of technology,2007.

[7] Pang Zi-rui, Li Jian-zhuang, CaiGuang-qi. CBN grinding wheel feature selection based on 
ultra-high speed grinding[J]. Machinery manufacturing,2007,45(510):30-32.

[8] Sheng Xiao-min, Mi Hai-qing. Auto high-speed precision grinding camshaft processing key technology[J]. New technology and new technology,2008,(8):61-64.

[9] Liu Yi-lin, Peng Bi, Zhang Shang, Zheng Meng-kun. High-speed camshaft grinding machine for grinding wheel rack body finite element analysis[J]. Machinery manufacturing,2012,50(579):11-13.

[10] Du Ping-an. The basic of finite element mesh division[J].Machinery design and manufacturing,2000,(1):34-36. 